\title{
A review of sources of systematic errors and uncertainties in observations and simulations at $183 \mathrm{GHz}$
}

\author{
Hélène Brogniez ${ }^{1}$, Stephen English ${ }^{2}$, Jean-François Mahfouf ${ }^{3}$, Andreas Behrendt $^{4}$, Wesley Berg ${ }^{5}$, Sid Boukabara $^{6}$, \\ Stefan Alexander Buehler ${ }^{7}$, Philippe Chambon ${ }^{3}$, Antonia Gambacorta ${ }^{8}$, Alan Geer ${ }^{2}$, William Ingram ${ }^{9}$, \\ E. Robert Kursinski ${ }^{10}$, Marco Matricardi ${ }^{2}$, Tatyana A. Odintsova ${ }^{11}$, Vivienne H. Payne ${ }^{12}$, Peter W. Thorne ${ }^{13}$, \\ Mikhail Yu. Tretyakov ${ }^{11}$, and Junhong Wang ${ }^{14}$ \\ ${ }^{1}$ LATMOS (IPSL/UVSQ/UPMC/CNRS), 78280, Guyancourt, France \\ ${ }^{2}$ ECMWF, Reading, RG2 9AX, UK \\ ${ }^{3}$ CNRM/GAME, Météo-France/CNRS, Toulouse, 31057, France \\ ${ }^{4}$ University of Hohenheim, Institute of Physics and Meteorology, 70599 Stuttgart, Germany \\ ${ }^{5}$ Colorado State University, Fort Collins, CO, USA \\ ${ }^{6}$ NOAA, USA, Camp Spring, MD, USA \\ ${ }^{7}$ Meteorological Institute, Center for Earth System Research and Sustainability, University of Hamburg, Hamburg, Germany \\ ${ }^{8}$ Science and Technology Corporation, Columbia, MD, USA \\ ${ }^{9}$ MetOffice, Hadley Centre, Exeter, UK and AOPP, Department of Physics, Oxford, UK \\ ${ }^{10}$ Space Sciences and Engineering, Boulder, CO, USA \\ ${ }^{11}$ Institute of Applied Physics of the Russian Academy of Science, Nizhny Novgorod, Russia \\ ${ }^{12}$ JPL, California Institute of Technology, Pasadena, CA, USA \\ ${ }^{13}$ Department of Geography, Maynooth University, Maynooth, Ireland \\ ${ }^{14}$ State University of New York, Albany, NY, USA \\ Correspondence to: Hélène Brogniez (helene.brogniez@latmos.ipsl.fr)
}

Received: 12 January 2016 - Published in Atmos. Meas. Tech. Discuss.: 29 January 2016

Revised: 25 April 2016 - Accepted: 29 April 2016 - Published: 18 May 2016

\begin{abstract}
Several recent studies have observed systematic differences between measurements in the $183.31 \mathrm{GHz}$ water vapor line by space-borne sounders and calculations using radiative transfer models, with inputs from either radiosondes (radiosonde observations, RAOBs) or short-range forecasts by numerical weather prediction (NWP) models. This paper discusses all the relevant categories of observation-based or model-based data, quantifies their uncertainties and separates biases that could be common to all causes from those attributable to a particular cause. Reference observations from radiosondes, Global Navigation Satellite System (GNSS) receivers, differential absorption lidar (DIAL) and Raman lidar are thus overviewed. Biases arising from their calibration procedures, NWP models and data assimilation, instrument biases and radiative transfer models (both the models themselves and the underlying spectroscopy) are presented and
\end{abstract}

discussed. Although presently no single process in the comparisons seems capable of explaining the observed structure of bias, recommendations are made in order to better understand the causes.

\section{Introduction}

Recent cross-comparisons between the existing nadir satellite microwave sounders of the tropospheric humidity using the $183.31 \mathrm{GHz}$ line, SAPHIR (Sondeur Atmosphérique du Profil d'Humidité Intertropicale par Radiométrie), ATMS (Advanced Technology Microwave Sounder), SSMI/S (Special Sensor Microwave Imager/Sounder) and MHS (Microwave Humidity Sounder) (instrument details are provided in Table 1; see the Appendix for a summary of all abbre- 
viations used in the paper), show very good agreement between them, with a $0.3-0.7 \mathrm{~K}$ range of mean difference, well within the radiometric noises of the instruments (Wilheit et al., 2013; Moradi et al, 2015). However, comparing the measurements to radiative transfer model (RTM) calculations, using profiles of temperature and humidity either from radiosondes (radiosonde observerations, RAOBs) or from numerical weather prediction (NWP) models, shows a channeldependent bias increasing from the center to the wings of the line. It was only with the arrival of ATMS and SAPHIR, both launched in October 2011, that the spectral shape of the bias became clear (Clain et al., 2015; Moradi et al., 2015). Indeed, these two instruments sample the $183.31 \mathrm{GHz}$ line five and six times respectively between the line center (providing humidity information for the upper troposphere, above $300 \mathrm{hPa}$ ) and line wings (up to $11 \mathrm{GHz}$ from the line center, for lower tropospheric sounding) compared to only three times for SSMI/S, MHS and AMSU-B (Advanced Microwave Sounding Unit-B that preceded MHS onboard NOAA 15, 16 and 17). The observed minus calculated brightness temperatures (BTs) are shown in Fig. 1, for SAPHIR, ATMS, MHS and SSMI/S using temperature and humidity profiles either from RAOBs or NWP systems (Météo-France and European Centre for Medium-range Weather Forecasts, ECMWF). The radiances are calculated using RTTOV.v11 RTM (Radiative Transfer for the Television InfraRed Observation Satellite (TIROS) Operational Vertical Sounder; Eyre, 1991; Saunders et al., 1999; Matricardi et al., 2004; Saunders et al., 2013). A consistent spectrally dependent bias is found that is larger further from the line center. Figure 2 presents two maps of the differences between the observed ATMS BTs and the calculated BTs from the all-sky first-guess fields of the ECMWF NWP system for channels $22(183 \pm 1 \mathrm{GHz})$ and $18(183 \pm 7 \mathrm{GHz})$ for a 2 month period. While large differences can be seen in areas with a high occurrence of optically thick (at $183 \mathrm{GHz}$ ) ice clouds, there is a clear background difference, between $60^{\circ} \mathrm{N}$ and $60^{\circ} \mathrm{S}$, that increases towards the line wings and that cannot be related to a particular region or atmospheric state.

Knowledge of absolute errors is important for climate applications such as reanalysis, where the need to detect small changes in the mean state is paramount. For real-time NWP, knowing absolute values is less important because observations are bias-corrected, with state-of-the-art NWP systems updating the corrections frequently. Bias-corrected observations at $183 \mathrm{GHz}$ are used widely in NWP models and have important impacts (Geer et al., 2014). However, the absolute errors in the short-range forecast are also not well known. If sources of systematic errors can be reduced, the need for bias correction would also be reduced, and perhaps one day could be eliminated completely, allowing $183 \mathrm{GHz}$ observations to become a reference for humidity. This would enable us both to understand biases in other humidity observations better and to improve the separation of biases arising from the model (such as cloud cover) from others (such as humidity fields).

The attribution of the biases requires discussion of all the relevant observational data and model results, quantification of their uncertainties and separation of biases that could be common to all approaches from those attributable to some particular methodology; thus we need reference observations from RAOBs, Global Navigation Satellite System (GNSS) receivers, differential absorption lidar (DIAL) and Raman lidar. We can then attribute biases arising from their calibration procedures, NWP models and data assimilation, instrument biases and RTMs (both the models themselves and the underlying spectroscopy).

If we can successfully attribute the biases then it becomes possible to work on a solution to remove them at source. To illustrate this, consider the case of a new observation type for humidity. If we believe that there is a calibration error and we can characterize this error accurately, it may become clear to instrument engineers why the bias exists. If the bias is a combination of contributions from a number of sources, this process cannot happen. This is also the motivation behind projects such as GAIA-CLIM (Gap Analysis for Integrated Atmospheric ECV - Essential Climate Variable - Climate Monitoring, http://www.gaia-clim.eu/) and FIDUCEO (Fidelity and Uncertainty in Climate Data record from Earth Observations, http://www.fiduceo.eu/), which are also attempting to provide a more accurate assessment of systematic biases in observations.

\section{State-of-the-art in observation and modeling}

\subsection{Reference water vapor measurements}

\subsubsection{Radiosondes}

Uncertainties in relative humidity $(\mathrm{RH})$ measurements by in situ probes arise mainly from pre-launch calibration procedures, calibration corrections, time lags and (for some probes) solar radiation heating of the sensor. The GCOS Reference Upper-Air Network (GRUAN, http://www.gruan. org) aims to establish a network of temperature and humidity measurements with traceability to SI standards, and best possible characterization of uncertainties (Dirksen et al., 2014; Bodeker et al., 2015). For the Vaisala RS92-SGP (hereafter RS92), one of the most common RAOBs probes used operationally and during field campaigns, the GRUANcharacterized uncertainty in RH measurements after correcting known biases is overall below $6 \% \mathrm{RH}$, and the only uncorrected bias is a dry bias of $\sim 5 \% \mathrm{RH}$ at night for temperatures colder than $-40^{\circ} \mathrm{C}$ (Dirksen et al., 2014). The reliability of the RS92 product in the troposphere has been verified by comparisons with Frost Point Hygrometer (FPH) measurements, which are highly accurate balloon-borne humidity measurements, in both tropical and extratropical regions. 


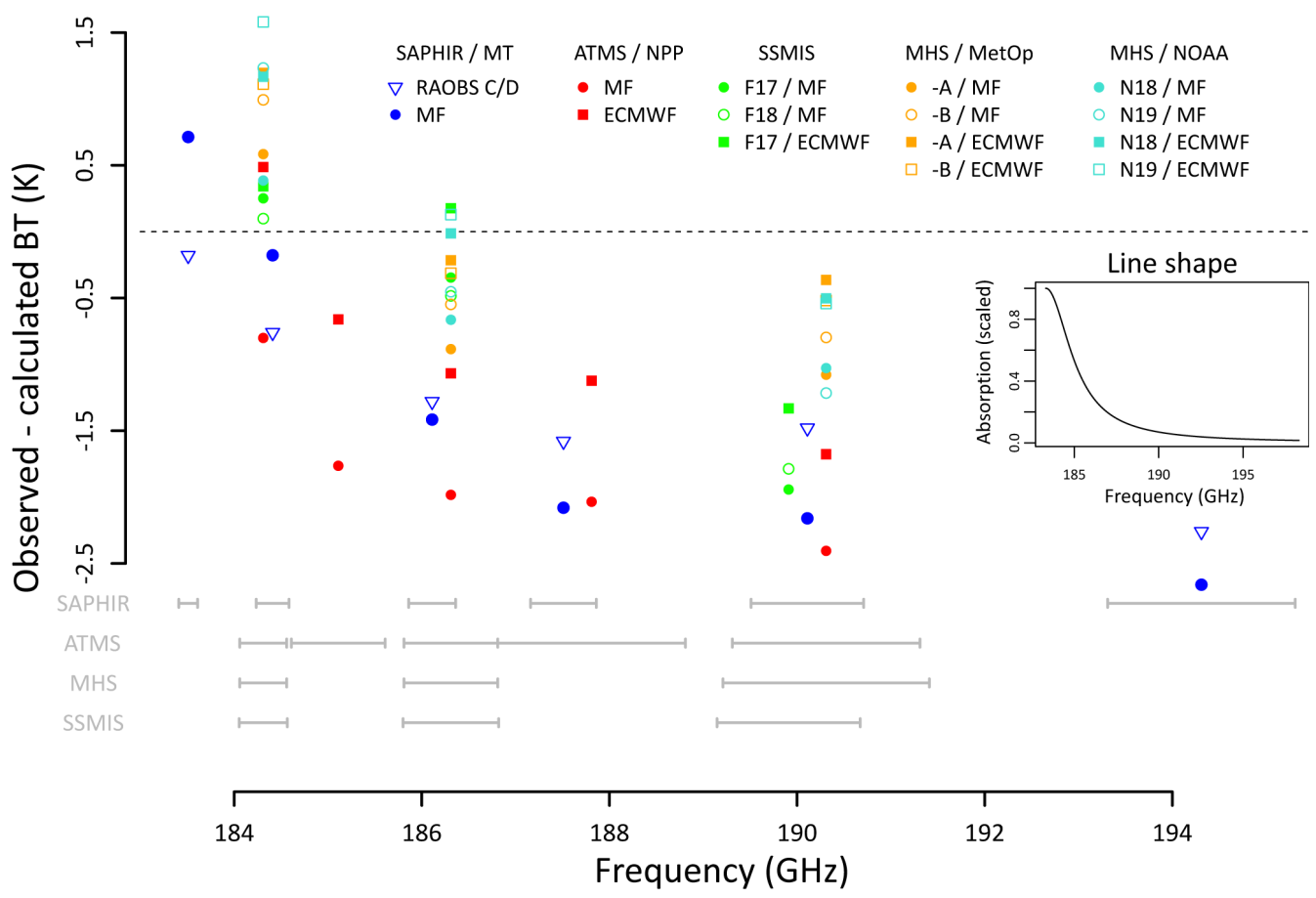

Figure 1. Mean observed BT minus calculated BT. All the calculated BTs are from RTTOVv11 run on RAOBs measurements (triangles) or Météo France NWP profiles (MF, circles) or European Centre for Medium-range Weather Forecasts NWP profiles (ECMWF, squares). Each color refers to a specific sensor, as in the legend. The horizontal gray bars indicate the width of the band passes. For simplicity, only one side of the absorption line is represented. The RAOB measurements were collected during the CINDY/DYNAMO/AMIE field campaign, winter 2011-2012. The inset is a scaled representation of the $183.31 \mathrm{GHz}$ line, assuming a Van Vleck-Weisskopf shape.

Table 1. List of satellites, sensors and their channels located in the $f_{0}=183.31 \mathrm{GHz}$ absorption line. To reach the required radiometric accuracy, the sensors are double-sided channels (except channel 3 of MHS), with the same bandwidth on each side; for each channel, radiation is measured over each side and averaged.

\begin{tabular}{|c|c|c|c|c|c|}
\hline Satellite & Instrument name & $\begin{array}{l}\text { Scanning geometry, maximum satellite } \\
\text { zenith angle }\left(\theta_{\text {zen }}, \text { in }^{\circ}\right) \text {, swath width } \\
(\mathrm{km}) \text { and number of pixels/samples per } \\
\text { scan line }\end{array}$ & $\begin{array}{l}\text { Channels around } \\
f_{0}=183.31 \mathrm{GHz} \\
(\mathrm{GHz})\end{array}$ & $\begin{array}{r}\text { Bandwidth } \\
\text { (MHz) }\end{array}$ & $\begin{array}{r}\text { In-flight radiometric } \\
\text { accuracy }(\mathrm{K})\end{array}$ \\
\hline Suomi-NPP & $\begin{array}{l}\text { ATMS } \\
\text { (Advanced Technology } \\
\text { Microwave Sounder) }\end{array}$ & $\begin{array}{l}\text { cross-track } \\
\theta_{\text {zen }}= \pm 64^{\circ} \\
\text { swath width }=2503 \mathrm{~km} \\
96 \text { samples }\end{array}$ & $\begin{array}{l}f_{0} \pm 1.0 \\
f_{0} \pm 1.1 \\
f_{0} \pm 2.8 \\
f_{0} \pm 4.2 \\
f_{0} \pm 7.0\end{array}$ & $\begin{array}{r}500 \\
1000 \\
1000 \\
2000 \\
2000\end{array}$ & $\begin{array}{l}0.9 \\
0.8 \\
0.8 \\
0.8 \\
0.8\end{array}$ \\
\hline $\begin{array}{l}\text { MetOp-A/B } \\
\text { NOAA-18/19 }\end{array}$ & $\begin{array}{l}\text { MHS } \\
\text { (Microwave Humidity } \\
\text { Sounder) }\end{array}$ & $\begin{array}{l}\text { cross-track } \\
\theta_{\text {zen }}= \pm 50^{\circ} \\
\text { swath } \quad \text { width }=1920 \mathrm{~km} \\
90 \text { contiguous pixels }\end{array}$ & $\begin{array}{l}f_{0} \pm 1.0 \\
f_{0} \pm 3.0 \\
f_{0}+7.0\end{array}$ & $\begin{array}{l}1000 \\
2200\end{array}$ & $\begin{array}{l}0.70 \\
0.84\end{array}$ \\
\hline
\end{tabular}


The GRUAN RS92 humidity profile does not vary greatly from Vaisala's default processing below the upper troposphere below $200 \mathrm{hPa}$ (Yu et al., 2015). Further, the most recent intercomparison campaign (Nash et al., 2011) held in Yangjiang $\left(21^{\circ} \mathrm{N}, 111^{\circ} \mathrm{E}\right.$; South China) showed good agreement between RS92 and most other operational RAOBs up to the middle to upper troposphere above $500 \mathrm{hPa}$, and also with FPH measurements (Vömel et al., 2007). In the lower to mid-troposphere there is therefore robust agreement and evidence that RAOBs biases could at most be a few percent, with somewhat broader random sampling uncertainties on individual profiles. Additionally, a given fractional change error in humidity, similar to the accuracy of the sensor, causes a considerably smaller fractional change of BTs. Therefore RAOBs errors could only explain substantial biases near the line center, where the opacity is highest and is thus sensitive to water vapor in the upper part of the troposphere; whereas the observed $183 \mathrm{GHz}$ biases are the largest towards the wings (typical weighting functions of SAPHIRand AMSU-B-like sounders can be found in Brogniez et al., 2013, Fig. 2).

\subsubsection{GNSS receivers}

Ground-based GNSS estimates of the atmospheric precipitable water (PW) rely on the measurement of the zenith total delay, the sum of terms due to water vapor (the "wet" delay) and to the dry gases of the troposphere (the "dry" delay). The GNSS-estimated PW has an uncertainty of $\sim 2 \%$ in the mean $(<1.0 \mathrm{~mm})$ (Ning et al., 2016). However, a recent analysis of the upper-air sounding network deployed during the CINDY/DYNAMO/AMIE field campaign has revealed a statistically significant dry bias, of unclear origin, in the GNSS values $(\sim 2.0 \mathrm{~mm}$ in $\mathrm{PW})$ in moist conditions at some sites (Ciesielski et al., 2014). Understanding of this dry bias might contribute to the current discussion on the $183 \mathrm{GHz}$ bias. Indeed, since the wings of the $183.31 \mathrm{GHz}$ line are mainly sensitive to the lower tropospheric humidity, and the PW is dominated by the humidity content of the lower troposphere, the analysis of the GNSS-estimated PW provides hints at the potential for a contribution of the PW to the overall $183 \mathrm{GHz}$ biases.

\subsubsection{Lidar systems}

Two types of lidars are used to measure water vapor profiles (Behrendt et al., 2007; Bhawar et al., 2011). Differential absorption lidars (DIAL) measure the water vapor number density with two backscatter signals, at adjacent near-infrared (IR) wavelengths with high - online - and low - offline - absorption, yielding a self-calibrating system. It only relies on the difference of the water vapor absorption cross sections $\sigma_{\text {on }}$ and $\sigma_{\text {off }}$ at these two wavelengths (thus eliminating any bias common to both cross sections). Raman lidars are based on the inelastic scattering by water vapor molecules, and require one instrument-dependent calibration factor for all heights to obtain the mixing ratio. All lidar systems provide data in the cloud-free atmosphere, or until the laser beam reaches an optically thick cloud. Performance simulations as well as intercomparisons have confirmed accuracies $<5 \%$ in the troposphere for both types of systems (Wulfmeyer et al., 2015). Comparisons between water vapor profiles measured by lidar and by radiosondes further support the accuracy estimates for the global radiosonde data in the troposphere, quoted above.

\subsection{Radiative transfer modeling and spectroscopy}

\subsubsection{Behavior of radiative transfer models}

Many cross-comparisons of microwave (MW) RTMs have been performed over the years. For instance, Garand et al. (2001) compared several reference and fast models (including RTTOV.v5 and v6, Saunders et al., 1999) used by the operational NWP community for the $183 \pm 1 \mathrm{GHz}$ channels. They found that models then agreed overall better than $0.5 \mathrm{~K}$ in BT, which is consistent with the results of Melsheimer et al. (2005), a study dedicated to line-by-line RTMs, with differences within roughly $0.5,1.5$ and $2.5 \mathrm{~K}$, respectively for $183 \pm 1, \pm 3$ and $\pm 7 \mathrm{GHz}$ channels (channels 3 to 5 of AMSU-B and MHS). The differences were mainly attributed to the differences in spectroscopy (line parameters and continua) and not the RTMs themselves. This was confirmed by Buehler et al. (2006), who showed that on average over the globe, the difference between two independent models, RTTOV.v7 and the line-by-line model ARTS (Atmospheric Radiative Transfer Simulator; Buehler et al., 2005a; Eriksson et al., 2011) is between $0.01 \mathrm{~K}$ for the $183 \pm 1 \mathrm{GHz}$ channel and $0.2 \mathrm{~K}$ for the $183 \pm 7 \mathrm{GHz}$ channel, except for a few extreme situations. More recently, Chen et al. (2010) have shown that, on a sample of diverse atmospheric profiles, fast and line-by-line RTMs agree within $0.1 \mathrm{~K}$ for MHS channels, and that this result was highly stable under humid conditions. In their evaluation of SAPHIR using RAOBs, Clain et al. (2015) have shown that the three RTMs, RTTOV.v10, ARTS and MonoRTM (Monochromatic Radiative Transfer Model; Clough et al., 2005; Payne et al., 2011), provide fairly consistent BTs on a common set of tropical profiles, the differences being in the range $-1.50 \mathrm{~K} / 0.78 \mathrm{~K}$, with the largest differences observed for the central channel $(183 \pm 0.2 \mathrm{GHz})$. These three RTMs rely on the currently most widely accepted model MT_CKD (MlawerTobin_CloughKneisysDavies; Mlawer et al., 2012) for the parametrization of the absorption due to the water vapor continuum.

Interestingly, patterns found in the IR are similar in terms of dependence on distance from the line center. Indeed, sensitivity studies on a sample of channels in the $6.3 \mu \mathrm{m}$ water vapor band of the IASI (Infrared Atmospheric Sounding Interferometer) instrument carried out using RTTOV.v11 showed 
that the difference between calculated and observed BTs increases as the peak altitude of the weighting functions shifts downwards. The same qualitative behavior is observed irrespective of the atmospheric state used in the simulations (i.e., either RAOBs or NWP data). It was also found that, on a purely empirical basis, the pattern of increasing bias can be removed by applying adjustments to the humidity fields input to the simulations (3 to $10 \%$ increase below $500 \mathrm{hPa}$ ) and/or to the strength of the continuum absorption (30\% increase in foreign continuum plus a $20 \%$ increase of self-continuum). This does not necessarily mean that the same mechanisms must be responsible for the biases observed in the MW radiances, even though the continuum model MT_CKD covers both spectral regions. The MT_CKD model is semiempirical and thus could have different biases in the IR and the MW spectral regions.

\subsubsection{Spectroscopy status}

One of the considerations for the accuracy of the line-byline radiative transfer (RT) models is the spectroscopic input for the modeling of molecular absorption. The main contributions to the molecular absorption in the $\mathrm{MW}$ region of the spectrum are from $\mathrm{H}_{2} \mathrm{O}, \mathrm{O}_{2}$ and $\mathrm{N}_{2}$, with some minor contributions from $\mathrm{O}_{3}$ and $\mathrm{N}_{2} \mathrm{O}$. For instance John and Buehler (2004) found that absorption by $\mathrm{O}_{3}$ leads to a decrease of up to $0.5 \mathrm{~K}$ in the $183 \pm 1 \mathrm{GHz}$ channel of MHS using ARTS, with even smaller values for the other channels. Additional sensitivity tests performed by Clain et al. (2015) using MonoRTM showed that the impact is also marginal in the $183.31 \pm 11 \mathrm{GHz}$ channel of SAPHIR $(0.05 \mathrm{~K}$ on average). The details of how the molecular absorption is modeled may vary between different models, but the overall absorption is most commonly calculated for both the contribution near the line centers and the smoothly varying continuum.

Line parameters (line position and strength, the airbroadened half-width, the self-broadened half-width, the temperature exponent of the width and the pressure shift) may be obtained from laboratory experiments or from theoretical calculations and are collected in databases such as the widely used the high-resolution transmission compilation (HITRAN, Rothman et al., 2013). The current edition of HITRAN provides the parameters for Voigt profiles, but future editions of the database will allow for inclusion of additional parameters for more sophisticated line shape models (Tennyson et al., 2014). Sensitivity tests on Voigt parameters, performed using MonoRTM, have shown that illustrative uncertainties on the foreign $( \pm 3 \%)$ and self-broadened $( \pm 15 \%)$ half widths, on the temperature exponent (maximum of $15 \%$ ) and the pressure shift (maximum of $20 \%$ ) are certainly too small to explain the observed bias (Payne et al., 2008), and the spectroscopic community (lab and modellers) believes that the accuracy of these parameters is higher than the above numbers. The uncertainty of the dry air absorption including dry continuum and resonance absorption by $\mathrm{O}_{2}$,
$\mathrm{O}_{3}, \mathrm{~N}_{2} \mathrm{O}, \mathrm{NO}, \mathrm{CO}$ and other minor atmospheric constituents, as well as uncertainty related to wings of neighboring water lines is not thought to be large enough to account for the observed model-measurement bias.

The physical origin and properties of the water vapor continuum have been debated and probed with measurements for decades. In the current version of the MT_CKD continuum model, water vapor contributions are modeled as monomer absorption, and the spectral variation of the continuum is assumed to be extremely smooth (sampled every $300 \mathrm{GHz}$ in MT_CKD). Figure 3 summarizes comparisons of the continuum coefficients obtained from known laboratory and field ( $\sim 1 \mathrm{~km}$ path along the surface, and thus insensitive to the vertical distribution of absorbers) measurements (shown by symbols) against the continuum parameters (dotted and dashed lines) that provide agreement with groundto-sky radiometric data in MT_CKD. It shows discrepancies (offsets in a log scale) that are not yet understood. There is thus an inconsistency between two large sets of experimental data, namely laboratory (together with surface path measurements) and radiometric measurements. This is confirmed by Payne et al. (2011) who concluded that for atmospheric path lengths the combination of MPM (Millimeter-wave Propagation Model, Liebe, 1989; Rosenkranz, 1998) foreign and self-continuum (solid lines in Fig. 3) is inconsistent with the radiometric measurements (looking up) at high column water vapor amounts.

Finally, recent laboratory studies have resulted in unambiguous detection of $\mathrm{H}_{2} \mathrm{O}$ dimer absorption in the millimeterwave range (Tretyakov et al., 2013; Serov et al., 2014) and to the development of a model to describe it (Odintsova et al., 2014). This absorption shows spectral variation on scales that are not accounted for in the current version of MT_CKD or in Liebe-based models. Odintsova et al. (2014) indicate that the inclusion of dimer absorption can result in small-scale spectral $(\sim 1 \mathrm{GHz})$ variation of 0.5 to $1 \mathrm{~K}$ in up-looking (groundbased) spectra. The impact of accounting for dimer absorption on RT modeling for the $183 \mathrm{GHz}$ satellite radiometer channels has yet to be determined.

\subsection{Water vapor analysis}

In NWP models, the main observation types influencing humidity analyses are in situ data like RAOBs and remote sensing observations from IR and MW sensors (Andersson et al., 2005). Cai and Kalnay (2005) have illustrated how a balance can arise between a forecast model (subject to a inherent bias with respect to the truth) and observations (with different bias characteristics). Variational bias correction (VarBC) techniques have been developed to adaptively estimate, as part of the constrained optimization that also provides the best estimate of the latest atmospheric state, a bias correction for each of the various assimilated observations (Dee, 2005; Auligné et al., 2007). In order to anchor the bias corrections and the final humidity analysis, RAOBs are not bias-corrected in any 
Data period: 2015-10-31 / 2015-12-05 Suomi-NPP/ATMS channel 18

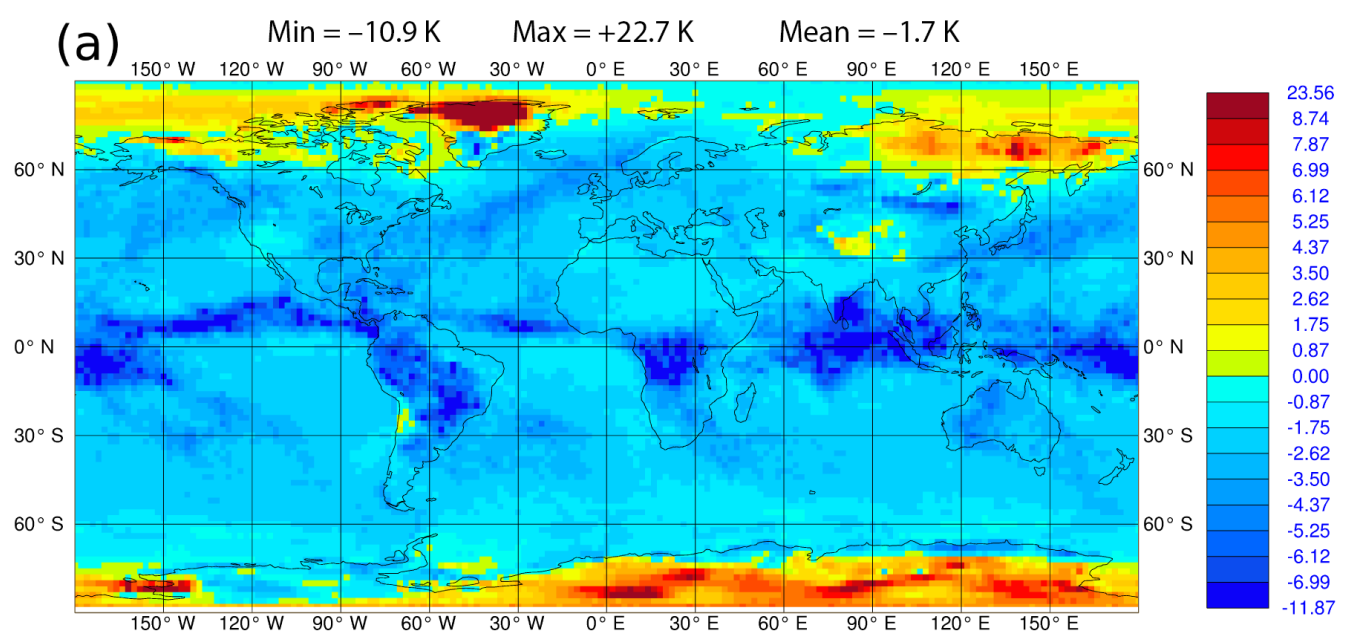

Data period: 2015-10-31 / 2015-12-05 Suomi-NPP/ATMS channel 22

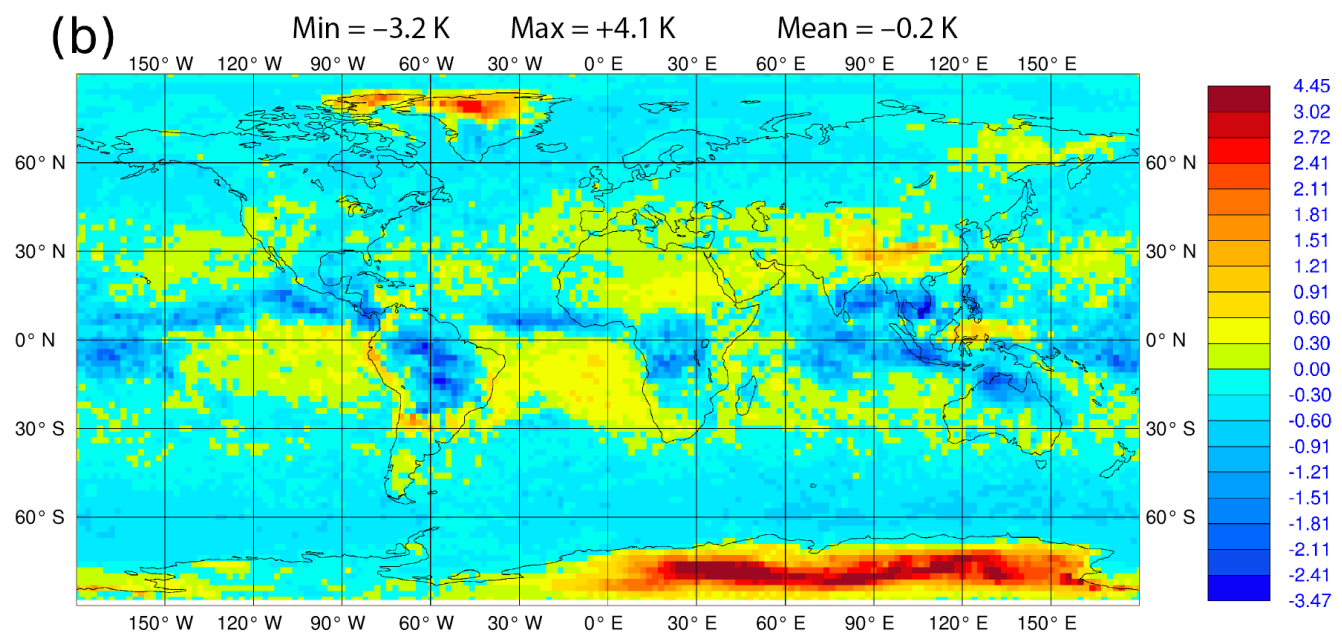

Figure 2. First-guess departures (observed BTs - those calculated from the forecast background) for Suomi-NPP/ATMS (a) channel 18 $(183 \pm 7 \mathrm{GHz})$ and $(\mathbf{b})$ channel $22(183 \pm 1 \mathrm{GHz})$ and the current ECMWF NWP system. The maps show the mean, with the global minima, maxima and means in the legend.

current VarBC scheme, but with static corrections such as the one proposed by Agusti-Panareda et al. (2009) with a standardization to night-time RS92 observations (which do not suffer from solar heating effects and hence exhibit lower uncertainties). Even though static corrections have known weaknesses (e.g., difficulty to separate RS92 reports biases corrected at the station from other sources, an assumption of homogeneous background error biases), these measurements are used to anchor the bias correction and the final humidity analysis in NWP systems. Hence it is possible that humidity analyses share similar biases to radiosondes, which might explain some of the consistency of the channel-dependent bias between in situ measurements and NWP simulations.
More investigations would be needed to test the impact of this anchoring, although it is expected from the discussion in Sect 2.1 that the effect would be more pronounced in the upper-tropospheric channels (close to the line center) than in the lower tropospheric channels (in the line wings).

An issue that affects most comparisons between $183 \mathrm{GHz}$ observations and model simulations is cloud detection. Indeed, clouds and precipitation are not usually included in MW radiative transfer simulations for NWP. The main reason is the difficulty in specifying the shape, density and particle size distribution of solid precipitation particles (Burns et al., 1997; Doherty et al., 2007; Geer and Baordo, 2014). Clouds and precipitation tend to reduce the $183 \mathrm{GHz}$ BTs, 


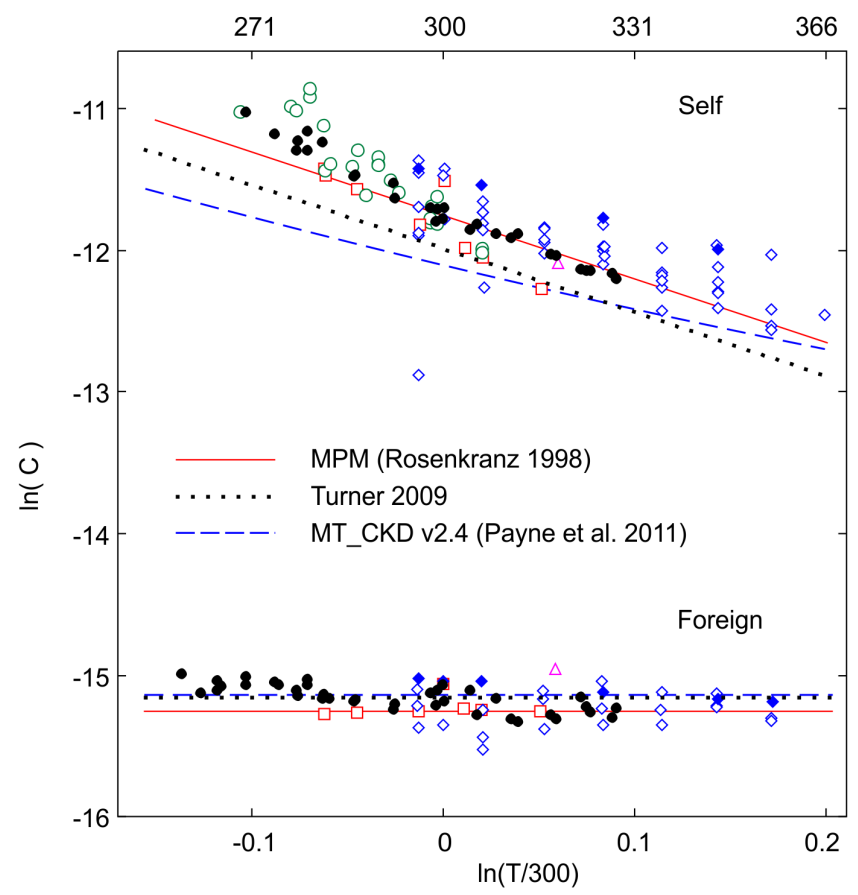

Figure 3. Self-broadened (pure water vapor or quadratic with humidity) and foreign-broadened (mixture with air or linear with humidity) continuum coefficients $\mathrm{C}$ (in $\left.\left(\mathrm{dB} \mathrm{km}^{-1}\right) /(\mathrm{GHz} \mathrm{kPa})^{2}\right)$, as in Rosenkranz (1998, 1999). Symbols are field and laboratory data (filled blue diamonds are from Kuhn et al., 2002; open blue diamonds are from Godon et al., 1992 and Bauer et al., 1993, 1995; green open circles are from Katkov et al., 1995; red squares are from Liebe, 1984 and Liebe and Layton, 1987; black dots are from Koshelev et al., 2011; pink triangles are from Becker and Autler, 1946). Statistical uncertainty of individual points in each series is approximately equal to or less than the size of the points. Solid lines are continuum coefficients derived by Rosenkranz (1998) for the Millimeter-wave Propagation Model (MPM). Dotted and dashed blue lines correspond to scaling of these coefficients on the basis of radiometric data suggested by Turner et al. (2009) and Payne et al. (2011).

particularly in the lower-peaking channels, either by scattering or by absorption, which shifts the altitude of the weighting function upwards. In situations where the cloud detection is failing to identify and therefore omits some cloud-affected scenes, the observed BTs would be lower than the simulated ones (see for instance the negative bias in the intertropical convergence zone in Fig. 2).

Different cloud screening methods are applied depending on the sensor and the channels available, leading to different accuracies of the cloud screening. For instance, ATMS offers a large suite of channels that can complement each other to separate clear and cloudy scenes (Bormann et al., 2013), while SAPHIR provides only channels in the $183.31 \mathrm{GHz}$ line, giving fewer possibilities for cloud detection (Chambon et al., 2015). Several filtering techniques using only $183 \mathrm{GHz}$ channels exist, relying on the strong reduction in BT induced by scattering and/or absorption, which can reach up to $20 \mathrm{~K}$ in regions of intense convection (Greenwald and Christopher, 2002; Hong et al., 2005; Buehler et al., 2007). However, it is difficult to screen all clouds, so residual signals due to clouds must be expected to be present. The all-sky first guess departures from assimilation at ECMWF (e.g., Geer et al., 2014) are the only routinely computed differences in the $183.31 \mathrm{GHz}$ line which attempt to take into account the effects of cloud and precipitation in the radiative transfer modeling. Compared to those differences computed using clearsky radiative transfer and cloud-screening (which are shown in Fig. 1 marked ECMWF), the all-sky ATMS biases are smaller by $0.4 \mathrm{~K}$ in the $\pm 7 \mathrm{GHz}$ channel, suggesting some of the bias in the lower peaking channels can be explained by residual cloud effects.

\subsection{Space-borne microwave radiometers}

\subsubsection{Intercomparison of instruments}

Ways to compare measurements by different satellite instruments include the simultaneous nadir overpasses technique (limiting the comparisons to the highest latitudes, John et al., 2012) and the use of "natural targets" that have very little variability or the averaging over a lot of scenes (John et al., 2013a). Another technique is the double difference technique that uses NWP fields input to a RTM as a transfer function between two radiometers that have few common overpasses. Using this technique, recent comparisons of the $183 \mathrm{GHz}$ channel calibrations have been performed by the Global Precipitation Mission (GPM) intercalibration working group (XCAL team). Mean differences between the GMI (GPM Microwave Imager) BTs and the four operational MHS sensors onboard MetOp-A, MetOp-B, NOAA-18 and NOAA-19 as well as the Suomi-NPP ATMS and MeghaTropiques SAPHIR instruments are given in Table 2.

\subsubsection{Calibration issues}

Since GPM is in a precessing orbit with an inclination of $65^{\circ}$, it frequently crosses the orbits of the other sounders providing near-coincident observations several times each day in the $65^{\circ} \mathrm{N} / 65^{\circ} \mathrm{S}$ belt. Post-launch, a series of GPM calibration maneuvers was performed, and the resulting data were used to develop corrections for magnetic-induced biases, cross-track biases and updates to the pre-launch spillover corrections, as well as to verify the channel polarizations. The resulting GMI calibration is based on the data from these calibration maneuvers and does not depend on RTM. The GMI calibration is also completely independent of the calibration of the MHS, ATMS and SAPHIR instruments, thus providing a useful measure of the absolute calibration accuracy of the $183 \mathrm{GHz}$ channels for these sensors. The differences in Table 2 show consistent results, with values within $1 \mathrm{~K}$ for all channels and all sensors. Note that errors in the 
Table 2. Mean calibration differences versus the GPM GMI radiometer for the cross-track sounders listed in Table 1 (GMI - sounder) for channels near the $f_{0}=183.31 \mathrm{GHz}$ absorption line, computed by the GPM XCAL intercalibration team.

\begin{tabular}{llrr}
\hline Satellite & Instrument & $\begin{array}{r}\text { High-frequency channels } \\
\text { around } f_{0}=183.31 \mathrm{GHz}(\mathrm{GHz})\end{array}$ & $\begin{array}{r}\text { Calibration difference } \\
(\mathrm{K})\end{array}$ \\
\hline Megha-Tropiques & SAPHIR & $f_{0} \pm 0.2$ & 0.18 \\
& & $f_{0} \pm 1.1$ & -0.56 \\
& & $f_{0} \pm 2.8$ & -0.42 \\
& $f_{0} \pm 4.2$ & -0.66 \\
& & $f_{0} \pm 6.8$ & -0.32 \\
& & $f_{0} \pm 11.0$ & -0.41 \\
\hline Suomi-NPP & ATMS & $f_{0} \pm 1.0$ & 0.40 \\
& & $f_{0} \pm 1.8$ & -0.30 \\
& & $f_{0} \pm 3.0$ & -0.97 \\
& & $f_{0} \pm 4.5$ & -0.82 \\
MetOp-A & MHS & $f_{0} \pm 7.0$ & -0.78 \\
\hline MetOp-B & & $f_{0} \pm 1.0$ & 0.66 \\
& & $f_{0} \pm 3.0$ & -0.17 \\
& & $f_{0}+7.0$ & -0.14 \\
\hline NOAA-18 & MHS & $f_{0} \pm 1.0$ & 0.60 \\
& & $f_{0} \pm 3.0$ & 0.00 \\
& & $f_{0}+7.0$ & 0.09 \\
\hline NOAA-19 & MHS & $f_{0} \pm 1.0$ & 0.24 \\
& & $f_{0} \pm 3.0$ & -0.12 \\
& & $f_{0}+7.0$ & -0.06 \\
\hline & & $f_{0} \pm 1.0$ & 0.94 \\
& & $f_{0} \pm 3.0$ & 0.03 \\
& & $f_{0}+7.0$ & -0.05 \\
\hline
\end{tabular}

calibration of the SSMI/S $183 \mathrm{GHz}$ channels are substantially larger due to substantial biases caused by reflector emission and solar intrusion issues (Berg and Sapiano, 2013).

Finally, the receiver nonlinearity (i.e., the BT-to-count calibration curve) has been found to affect the BT by only a few tenths of a Kelvin across the passband (observed for GMI, D. Draper, Ball Aerospace, personal communication, 2015).

\subsubsection{Scan asymmetry}

Cross-track scanners sometimes show asymmetries across the swath, indicating issues related to the imperfectly known antenna pattern, which often evolve with the age of the instruments. Far from nadir, channels sounding deep into the troposphere, located on the wings of the $183.31 \mathrm{GHz}$ line, might be more affected by antenna issues than higher peaking channels, located in the center of the line, due to radiation measured by the side lobes. Such asymmetries were found for AMSU-B and MHS (Buehler et al., 2005b; John et al., 2013b), but so far the monitoring of SAPHIR has not shown any scan asymmetry. For ATMS, comparisons of temperature data records (TDRs, calibrated antenna temperatures) and sensor data records (SDRs, BT after further applying beam efficiency and scan-position-dependent bias corrections) for the $183 \mathrm{GHz}$ channels show the same behavior meaning that the TDR to SRD conversion is not responsible for the bias, although it seems to introduce some dependence on the viewing angle that warrants further investigation. For other sensors, in particular AMSU-B and MHS, this has so far not been thoroughly investigated, partly due to a lack of publicly available pre-launch measurements of antenna pattern.

\section{Recommendations}

\subsection{On the reference measurements}

Research on better characterization of uncertainties of the Vaisala RS92 measurements, and on offline corrections of biases, indicate that the remaining RAOBs biases could only explain discrepancies in the center of the $183.31 \mathrm{GHz}$ line, not in its wings. Nevertheless, cross-comparisons of water vapor measured by lidars and RAOBs and simulated by NWP models are strongly encouraged in order to confirm the spectral pattern of the $183 \mathrm{GHz}$ bias. Finally the next WMO upper-air intercomparison campaign is strongly encouraged to include the new Vaisala RS41 probes, which are likely to be even more accurate than the RS92 (Jensen et al., 2015). 


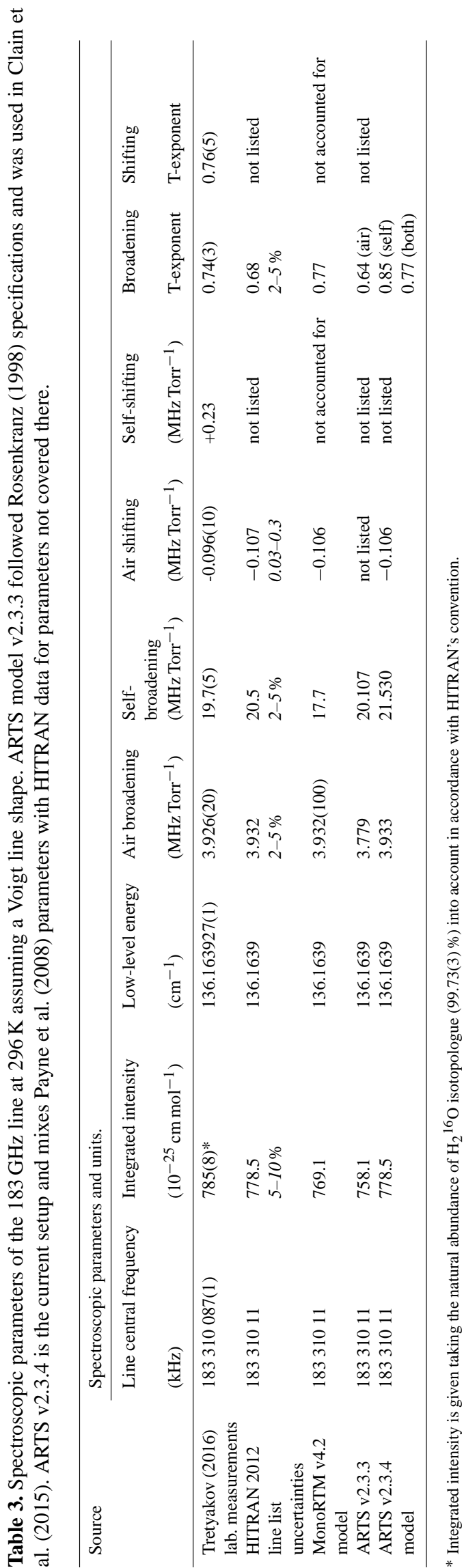

\subsection{On the radiative transfer and the spectroscopy}

For the purposes of atmospheric remote sensing, consistency with in situ atmospheric radiometric measurements is key. Currently, the cause of the apparent discrepancy between the laboratory measurements and the ground-based in situ results remains an open question. Continuation and augmentation of laboratory measurements are strongly encouraged to check the uncertainty levels for the main spectroscopic parameters, and to explore new line shape parametrizations. In addition, the use of ground-based $183 \mathrm{GHz}$ instruments can help to better constrain the parametrizations, because the surface does not contaminate the measurements. In particular, measurements at high values of precipitable water $(>3 \mathrm{~cm})$ are required to constrain the self-broadened continuum. For instance, recent opacity measurements performed with the radio occultation active spectrometer ATOMMS (Active Temperature, Ozone Moisture Microwave Spectrometer, Kursinski et al., 2012) have shown two spectral discrepancies (Kursinski et al., 2016). The first discrepancy is a poor match between the Liebe-MPM93 model and the measured line shape within $4 \mathrm{GHz}$ of the $183.31 \mathrm{GHz}$ line center. In this interval, the HITRAN-based AM6.2 model of Scott Paine (Harvard-Smithonian Center for Astrophysics) matches the ATOMMS measurements very well, to $0.3 \%$. However, there is a significant spectral discrepancy in the wing of the line with respect to the AM6.2 modeled opacity, which is apparently lower than the measured opacity. Viewed from space, this would translate into a modeled BT that is higher than measured BT (the modeled radiation coming from deeper in the atmosphere). This result is consistent with the discrepancies between the satellite-based measurements and the modeled estimates under scrutiny here. Detailed understanding requires additional measurements and more quantitative examination. In particular, it is recommended that ATOMMS measurements be made from aircraft at a range of pressures in order to determine the true line shape variation with pressure. Finally these analyses should be further extended to limb measurements at $183 \mathrm{GHz}$, such as those done by MLS (Microwave Limb Sounder, on-board the Aura satellite), considered as a reference for the monitoring of stratospheric water vapor.

Better coordination between instrument and calibration experts and RTM modelers would also help to ensure that RT simulations are consistent with the most recent spectroscopy measurements.

\subsection{On the water vapor analysis}

The two main approaches to handling clouds (avoiding observations affected by cloud - the clear-sky approach; or using model cloud-fields and analyzing all data - the all-sky approach) give similar but not identical biases. This suggests that the method for handling clouds can only explain part of the bias, but further investigation is needed to determine its 
impact on the overall bias and its characteristics more precisely. Testing the impact of the RAOBs constraint in the bias correction schemes of NWP systems with respect to the various observing systems (MW, IR, GNSS) should also be performed.

\subsection{On the space-borne sounders}

The instrument spectral response functions (SRFs) are too often averaged over the pass bands and assumed to be rectangular when unknown. Therefore the pre-launch recording and permanent availability of digital data and metadata of SRFs and antenna patterns are strongly encouraged for future instruments. Moreover, in the future, it is considered likely that radio frequency interference may become a threat at $183 \mathrm{GHz}$. It is therefore important both to measure the band passes of the instrument accurately, and also to ensure there is no sensitivity to bands outside the protected frequency. This point reinforces the need to have (an easy) access to the SRF of each instrument, as well as the conversion procedures between counts/radiances/BT. The possible contribution of biases that could originate from the radiometric calibration and the gain compression nonlinearities, although recognized to be small compared to the amplitude of the differences, needs to be fully assessed to close the error budget due to calibration. Finally, biases arising from asymmetric effects for channels with widely spaced double-side bands, as SAPHIR does, may also have an impact on the spectral characteristics of the bias. The size and nature of this asymmetry needs to be accurately documented.

\section{Conclusions}

A number of recent comparisons between spaceborne measurements in the $183.31 \mathrm{GHz}$ absorption line and calculations using NWP or RAOBs profiles with RTMs have highlighted a channel-dependent bias. The mean differences between channels close to the center of the line and those located in the wings of the line can reach up to $3 \mathrm{~K}$. An overview of the possible sources of errors and uncertainties that arise from such a comparison has been performed and discussed in light of the current knowledge for each of them.

i. Errors and uncertainties in measurements with the RS92 radiosonde instruments, being the most commonly used during both field campaigns and operationally, could only explain biases in the center of the line associated with upper tropospheric moisture. A combined use of RAOBs, of PW derived from ground-based GNSS and of water vapor profiles from lidar systems should help to better attribute and understand the observed biases. ii. Intercomparison studies between microwave RTMs of varying complexity (line-by-line and fast models) show good consistency.

iii. Different spectroscopic inputs, necessary to describe molecular absorption, are used in the various RTMs. While the uncertainties related to the dry air absorption (dry continuum and resonance absorption) could not account for the observed biases, the water vapor continuum (foreign and self) currently is the focus of most of the discussions within the expert community. Inconsistencies between laboratory and radiometric measurements have been highlighted and are not yet understood. Moreover, the $\mathrm{H}_{2} \mathrm{O}$ dimer absorption, recently detected in the MW spectral domain, remains to be included in RTMs.

iv. The analysis of water vapor fields produced by NWP data assimilation systems points towards deficiencies in the cloud detection methods required to screen out the clouds and precipitation that are not usually included in RTMs. The resulting omission of some cloudy scenes tends to lower the $183 \mathrm{GHz}$ BT by scattering and/or absorption with respect to clear air situations. Tests on filtering techniques suggest that residual clouds contribute partly to the observed bias.

v. Beside the observed discrepancy between the measured and the calculated $183 \mathrm{GHz}$ BTs, comparisons of measurements from space-borne sensors at $183 \mathrm{GHz}$ using dedicated techniques show a very good level of agreement, within $1 \mathrm{~K}$ for all channels and all sensors. However, the lack of publicly available SRFs and antenna patterns for most sensors makes it difficult to close the error budget due to the instrument calibration.

For each of these terms, we have provided recommendations in order to guide future studies with the objective of further reducing the possible sources of errors and uncertainties. 
Appendix A: List of abbreviations

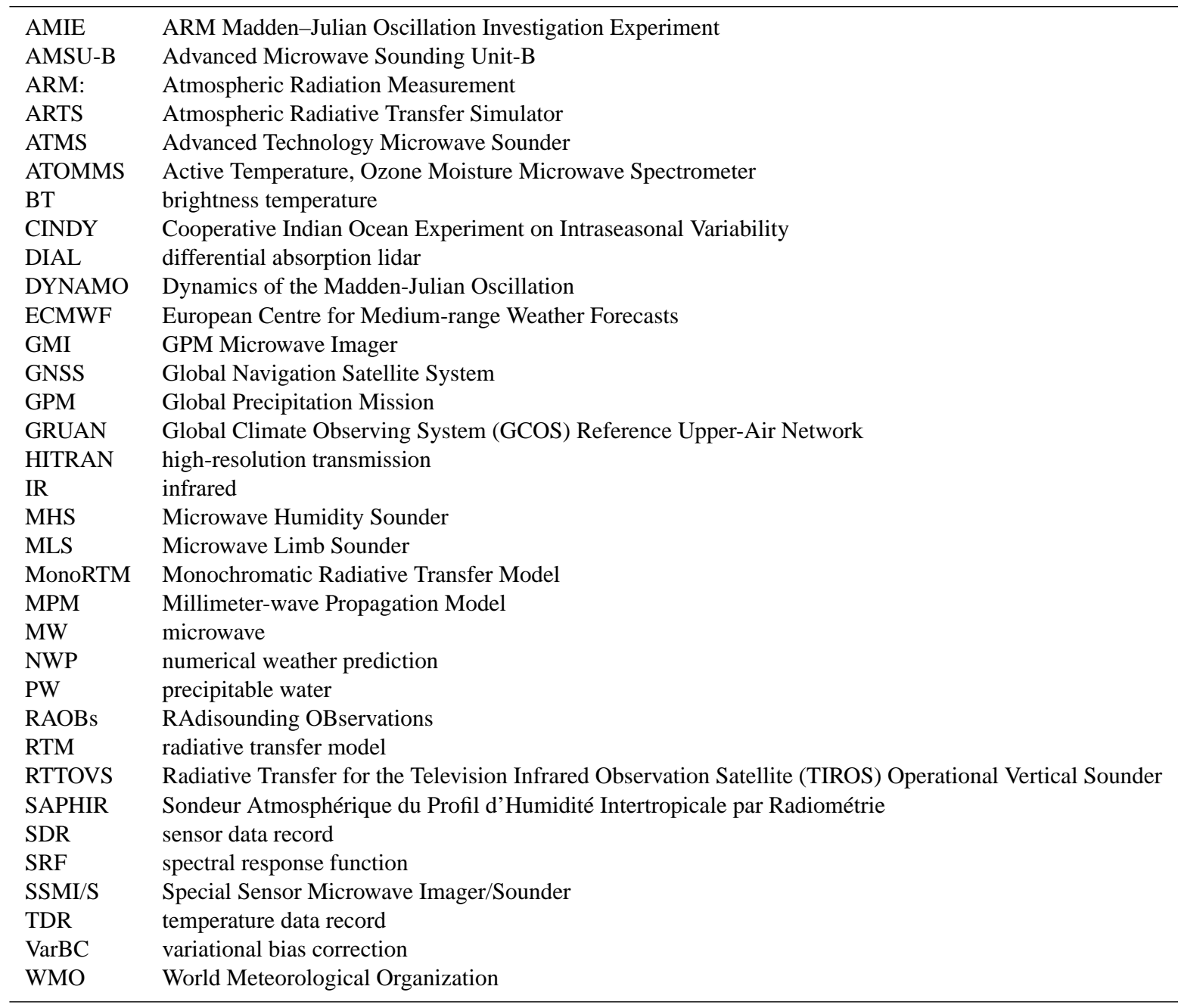


Acknowledgements. This paper reflects the outcomes of a workshop that was held 29-30 June 2015, in Paris. The process of identifying the key questions was performed during a series of working group sessions whose additional participants are thanked C. Accadia, R. Armante, P. Brunel, J. Bureau, M. Dejus, S. Di Michele, A. Doherty, C. Dufour, F. Duruisseau R. Fallourd, C. Goldstein, B. Ingleby, E. Kim, S. Laviola, A. Martini, V. Mattioli, L. Picon, C. Prigent, P. Sinigoj, N. Viltard. We warmly thank the CNES and Megha-Tropiques for the financial support of the workshop and also Sophie Cloché (IPSL) for her immense help in its organization. P.W Thorne was supported by the EU H2020 project GAIA-CLIM (Ares(2014)3708963/Project 640276). W. Ingram was funded by EUMETSAT through its Climate Monitoring Satellite Application Facility (CM-SAF). T.A Odintsova and M.Y Tretyakov acknowledge partial support from the Russian Foundation for Basic Research (RFBR). V. H. Payne was supported by a NASA Award from the Precipitation Measurement Mission Science Team. Part of this research was carried out at the Jet Propulsion Laboratory, California Institute of Technology, under a contract with the National Aeronautics and Space Administration. Reference herein to any specific commercial product, process or service by name, trademark, manufacturer or otherwise does not imply its endorsement by the United States government or the Jet Propulsion Laboratory, California Institute of Technology.

The three anonymous reviewers and B. Ingleby at ECMWF are acknowledged for their constructive and valuable comments that helped improved the manuscript. We finally thank O. Bobryshev for his contribution to the discussion of spectral line parameters.

Edited by: T. von Clarmann

\section{References}

Agusti-Panareda, A., Vasiljevic, D., Beljaars, A., Bock, O., Guichard, F., Nuret, M., Garcia Mendez, A., Andersson, E., Bechtold, P., Fink, A., Hersbach, H., Lafore, J.-P., Ngamini, J.B., Parker, D. J., Redelsperger, J.-L., and Tompkins, A. M.: Radiosonde humidity bias correction over the West African region for the special AMMA reanalysis at ECMWF, Q. J. Roy. Meteor. Soc., 135, 595-617, doi:10.1002/qj.396, 2009.

Andersson E., Bauer, P., Beljaars, A., Chevallier, F., Holm, E., Janiskova, M., Kallberg, P., Kelly, G., Lopez, P., McNally, A., Moreau, E., Simmons, A., Thépaut, J.-N., and Tompkins, A.: Assimilation and modeling of the atmospheric hydrological cycle in the ECMWF forecasting system, B. Am. Meteorol. Soc., 86, 3387-402, doi:10.1175/BAMS-86-3-387, 2005.

Auligné, T., McNally, A. P., and Dee, D. P.: Adaptive bias correction for satellite data in a numerical weather prediction system, Q. J. Roy. Meteor. Soc., 133, 631-642, doi:10.1002/qj.56, 2007.

Bauer, A., Godon, M., Carlier, J., Ma, Q., and Tipping, R. H.: Absorption by $\mathrm{H}_{2} \mathrm{O}$ and $\mathrm{H}_{2} \mathrm{O}-\mathrm{N}_{2}$ mixtures at $153 \mathrm{GHz}$, J. Quant. Spectrosc. Ra. Trans., 50, 463-475, 1993.

Bauer, A., Godon, M., Carlier, J., and Ma, Q.: Water vapor absorption in the atmospheric window at $239 \mathrm{GHz}$, J. Quant. Spectrosc. Ra. Trans., 53, 411-423, 1995.
Becker, G. E. and Autler, S. H.: Water vapor absorption of electromagnetic radiation in the centimeter wave-length range, Phys. Rev., 70, 300-307, 1946.

Behrendt, A., Wulfmeyer, V., Di Girolamo, P., Kiemle, C., Bauer, H.-S., Schaberl, T., Summa, D., Whiteman, D. N., Demoz, B. B., Browell, E. V., Ismail, S., Ferrare, R., Kooi, S., Ehret, $\mathrm{G}$, and Wang, J.: Intercomparison of water vapor data measures with lidar during IHOP_2002. Part I: Airborne to groundbased lidar systems and comparisons with chilled-mirror hygrometer radiosondes, J. Atmos. Oceanic Technol., 24, 3-21, doi:10.1175/JTECH1924.1, 2007.

Berg, W. and Sapiano, M.: Corrections and APC for SSMIS, Technical report, Colorado State University, available at: http:// rain.atmos.colostate.edu/FCDR/doc/ (last access: 12 May 2016), 2013.

Bhawar, R., Di Girolamo, P., Summa, D., Flamant, C., Althausen, D., Behrendt, A., Kiemle, C., Bosser, P., Cacciani, M., Champollion, C., Di Iorio, T., Engelmann, R., Herold, C., Müller, D., Pal, S., Wirthe, M., and Wulfmeyer, V.: The water vapour intercomparison effort in the framework of the Convective and Orographically-induced Precipitation Study: airborne-toground-based and airborne-to-airborne lidar systems, Q. J. Roy. Meteor. Soc., 137, 325-348, doi:10.1002/qj.697, 2011.

Bodeker, G., Bojinski, S., Cimini, D., Dirksen, R., Haeffelin, M., Hannigan, J., Hurst, D., Leblanc, T., Madonna, F., Maturilli, M., Mikalsen, A., Philipona, R., Reale, T., Seidel, D., Tan, D., Thorne, P., Vömel, H., and Wang, J.: Reference upper-air observations for climate: From concept to reality, B. Am. Meteorol. Soc., doi:10.1175/BAMS-D-14-00072.1, in press, 2015.

Bormann, N., Fouilloux, A., and Bell, W.: Evaluation and assimilation of ATMS data in the ECMWF system, J. Geophys. Res. Atmos., 118, 12970-12980, doi:10.1002/2013JD020325, 2013.

Brogniez, H., Kirstetter, P.-E., and Eymard, L.: Expected improvements in the atmospheric humidity profile retrieval using theMegha-Tropiques microwave payload, Q. J. Roy. Meteor. Soc., 139, 842-851 doi:10.1002/qj.1869, 2013.

Buehler, S. A., Eriksson, P., Kuhn, T., von Engeln, A., and Verdes, C.: ARTS, the Atmospheric Radiative Transfer Simulator, J. Quant. Spectrosc. Ra. Trans., 91, 65-93, doi:10.1016/j.jqsrt.2004.05.051, 2005a.

Buehler, S. A., Kuvatov, M., and John, V. O.: Scan asymmetries in AMSU-B data, Geophys. Res. Lett., 32, L24810, doi:10.1029/2005GL024747, 2005b.

Buehler, S. A., Courcoux, N., and John, V. O.: Radiative transfer calculations for a passive microwave satellite sensor: Comparing a fast model and a line-by-line model, J. Geophys. Res., 111, D20304, doi:10.1029/2005JD006552, 2006.

Buehler, S. A., Kuvatov, M., Sreerekha, T. R., John, V. O., Rydberg, B., Eriksson, P., and Notholt, J.: A cloud filtering method for microwave upper tropospheric humidity measurements, Atmos. Chem. Phys., 7, 5531-5542, doi:10.5194/acp-7-5531-2007, 2007.

Burns, B., Wu, X., and Diak, G.: Effects of precipitation and cloud ice on brightness temperatures in AMSU moisture channels, IEEE Trans. Geosci. Remote Sens., 35, 1429-1437, 1997.

Cai, M. and Kalnay, E.: Can reanalysis have anthropogenic climate trends without model forcing?, J. Climate, 18, 1844-1849, doi:10.1175/JCLI3347.1, 2005. 
Chambon, P., Meunier, L.-F., Guillaume, F., Piriou, J.-M., Roca, R., and Mahfouf, J.-F.: Investigating the impact of the water-vapour sounding observations from SAPHIR on board Megha-Tropiques for the ARPEGE global model, Q. J. Roy. Meteor. Soc., 141, 1769-1779, doi:10.1002/qj.2478, 2015.

Chen, Y., Han, Y., Van Delst, P., and Weng, F.: On water vapor jacobian in fast radiative transfer model, J. Geophys. Res., 115, D12303, doi:10.1029/2009JD013379, 2010.

Ciesielski, P. E., Yu, H., Johnson, R. H., Yoneyama, K., Katsumata, M., Long, C. N., Wang, J., Loehrer, S. M., Young, K., Williams, S. F., Brown, W., Braun, J., and Van Hove, R.: Quality-controlled upper-air sounding dataset for DYNAMO/CINDY/AMIE: development and corrections, J. Atmos. Oceanic Technol., 31, 741764, doi:10.1175/JTECH-D-13-00165.1, 2014.

Clain, G., Brogniez, H., Payne, V. H., John, V. O., and Luo, M.: An assessment of SAPHIR calibration using high quality tropical soundings, J. Atmos. Oceanic Technol., 32, 61-78, doi:10.1175/JTECH-D-14-00054.1, 2015.

Clough, S., Shephard, M., Mlawer, E., Delamere, J., Iacono, M., Cady-Pereira, K., Boukabara, S., and Brown, P.: Atmospheric radiative transfer modelling: a summary of the AER codes, J. Quant. Spectrosc. Ra. Trans., 91, 233-244, doi:10.1016j/j.jqsrt.2004.05.058, 2005.

Dee, D. P.: Bias and data assimilation, Q. J. Roy. Meteor. Soc., 131, 3323-3343, 2005.

Dirksen, R. J., Sommer, M., Immler, F. J., Hurst, D. F., Kivi, R., and Vömel, H.: Reference quality upper-air measurements: GRUAN data processing for the Vaisala RS92 radiosonde, Atmos. Meas. Tech., 7, 4463-4490, doi:10.5194/amt-7-4463-2014, 2014.

Doherty, A., Sreerekha, T. R., O'Keeffe, U. M., and English, S. J.: Ice hydrometeor microphysical assumptions in radiative transfer models at AMSU-B frequencies, Q. J. Roy. Meteor. Soc., 133, 1205-1212, 2007.

Eriksson, P., Buehler, S. A., Davis, C. P., Emde, C., and Lemke, O.: ARTS, the atmospheric radiative transfer simulator, Version 2, J. Quant. Spectrosc. Ra. Trans., 112, 1551-1558, doi:10.1016/j.jqsrt.2011.03.001, 2011.

Eyre J. R.: A fast radiative transfer model for satellite sounding systems, ECMWF Research Dept. Tech. Memo. 176, available from ECMWF, 1991.

Garand, L., Turner, D. S., Larocque, M., Bates, J., Boukabara, S., Brunel, P., Chevallier, F., Deblonde, G., Engelen, R., Hollingshead, M., Jackson, D., Jedlovec, G., Joiner, J., Kleespies, T., McKague, D. S., McMillin, L., Moncet, J.-L., Pardo, J. R., Rayer, P. J., Salathe, E., Saunders, R., Scott, N. A., Van Delst, P., and Woolf, H.: Radiance and jacobian intercomparison of radiative transfer models applied to HIRS and AMSU channels, J. Geophys. Res., 106, 24017-24031, 2001.

Geer, A. J. and Baordo, F.: Improved scattering radiative transfer for frozen hydrometeors at microwave frequencies, Atmos. Meas. Tech., 7, 1839-1860, doi:10.5194/amt-7-1839-2014, 2014.

Geer, A. J., Baordo, F., Bormann, N., and English, S.: All-sky assimilation of microwave humidity sounders, ECMWF technical memorandum 741, available at: http://www.ecmwf.int/en/ elibrary/technical-memoranda (last access: 12 May 2016), 2014.

Godon, M., Carlier, J., and Bauer, A.: Laboratory studies of water vapor absorption in the atmospheric window at $213 \mathrm{GHz}, \mathrm{J}$. Quant. Spectrosc. Ra. Trans., 47, 275-285, 1992.
Greenwald, T. J. and Christopher, S. A.: Effect of cold clouds on satellite measurements near $183 \mathrm{GHz}$, J. Geophys. Res., 107, 4170, doi:10.1029/2000JD000258, 2002.

Hong, G., Heygster, G., Miao, J., and Kunzi, K.: Detection of tropical deep convective clouds from AMSU-B water vapor channels measurements, J. Geophys. Res., 110, D05205, doi:10.1029/2004JD004949, 2005.

Immler, F. J., Dykema, J., Gardiner, T., Whiteman, D. N., Thorne, P. W., and Vömel, H.: Reference Quality Upper-Air Measurements: guidance for developing GRUAN data products, Atmos. Meas. Tech., 3, 1217-1231, doi:10.5194/amt-3-1217-2010, 2010.

Jensen, M. P., Holdridge, D., Survo, P., Lehtinen, R., Baxter, S., Toto, T., and Johnson, K. L.: Comparison of Vaisala radiosondes RS41 and RS92 at the ARM Southern Great Plains Site, Atmos. Meas. Tech. Discuss., 8, 11323-11368, doi:10.5194/amtd8-11323-2015, 2015.

John, V. O. and Buehler, S. A.: The impact of ozone lines on AMSU-B radiances, Geophys. Res. Lett., 31, L21108, doi:10.1029/2004GL021214, 2004.

John, V. O., Holl, G., Buehler, S. A., Candy, B., Saunders, R. W., and Parker, D. E.: Understanding inter-satellite biases of microwave humidity sounders using global simultaneous nadir overpasses, J. Geophys. Res., 117, D02305, doi:10.1029/2011JD016349, 2012.

John, V. O., Allan, R. P., Bell, B., Buehler, S. A., and Kottayil, A.: Assessment of inter-calibration methods for satellite microwave humidity sounders, J. Geophys. Res., 118, 4906-4918, doi:10.1002/jgrd.50358, 2013a.

John, V. O., Holl, G., Atkinson, N., and Buehler, S. A.: Monitoring scan asymmetry of microwave humidity sounding channels using simultaneous all angle collocations (SAACs), J. Geophys. Res., 118, 1536-1545, doi:10.1002/jgrd.50154, 2013b.

Katkov, V. Yu., Sverdlov, B. A., and Furashov, N. I.: Experimental estimates of the value and temperature dependence of the airhumidity quadratic component of the atmospheric water-vapor absorption coefficient in the frequency band of $140-410 \mathrm{GHz}$, Radiophys. Quantum Electr., 38, 835-844, 1995.

Koshelev, M. A., Serov, E. A., Parshin, V. V., and Tretyakov, M. Yu.: Millimeter wave continuum absorption in moist nitrogen at temperatures 261-328 K, J. Quant. Spectrosc. Ra. Trans., 112, 2704-2712, 2011.

Kuhn, T., Bauer, A., Godon, M., Buehler, S., and Kunzi, K.: Water vapor continuum: absorption measurements at $350 \mathrm{GHz}$ and model calculations, J. Quant. Spectrosc. Ra. Trans., 74, 545-562, 2002.

Kursinski, E. R., Ward, D., Stovern, M., Otarola, A. C., Young, A., Wheelwright, B., Stickney, R., Albanna, S., Duffy, B., Groppi, C., and Hainsworth, J.: Development and testing of the Active Temperature, Ozone and Moisture Microwave Spectrometer (ATOMMS) $\mathrm{cm}$ and mm wavelength occultation instrument, Atmos. Meas. Tech., 5, 439-456, doi:10.5194/amt-5-439-2012, 2012.

Kursinski, E. R., Ward, D., Otarola, A. C., McGhee, J., Stovern, M., Sammler, K., Reed, H., Erickson, D., McCormick, C., and Griggs, E.: Atmospheric profiling via satellite to satellite occultations near water and ozone absorption lines for weather and climate. Earth Observing Missions and Sensors: Development, Implementation, and Characterization IV, 10th SPIE Asia-Pacific Remote Sensing Symposium, New Delhi, India, 
4-7 April 2016, Proc. of SPIE Vol. 9881, Paper 9881-33, doi:10.1117/12.2224038, 2016.

Liebe, H. J.: The atmospheric water vapor continuum below 300 GHz, Int. J. Infr. Millimeter Waves, 5, 207-227, 1984.

Liebe, H. J.: MPM- An atmospheric Millimeter wave Propagation Model, Int. J. Infr. Millimeter Waves, 10, 631-65, 1989.

Liebe, H. J. and Layton, D. H.: Millimeter-wave properties of the atmosphere: Laboratory studies and propagation modeling, NTIA Rep. 87-224, Natl. Telecommun. and Inf. Admin., Boulder, Colorado, USA, 1987.

Matricardi, M., Chevallier, F., Kelly, G., and Thépaut, J.-N.: An improved general fast radiative transfer model for the assimilation of radiance observations, Q. J. Roy. Meteor. Soc., 130, 153-173, doi:10.1256/qj.02.181, 2004.

Melsheimer, C., Verdes, C., Buehler, S. A., Emde, C., Eriksson, P., Feist, D. G., Ichizawa, S., John, V. O., Kasai, Y., Kopp, G., Koulev, N., Kuhn, T., Lemke, O., Ochiai, S., Schreier, F., Sreerekha, T. R., Suzuki, M., Takahashi, C., Tsujimaru, S., and Urban, J.: Intercomparison of general purpose clear sky atmospheric radiative transfer models for the millimeter/submillimeter spectral range, Radio Sci., 40, RS1007, doi:10.1029/2004RS003110, 2005.

Mlawer, E., Payne, V., Moncet, J.-L., Delamere, J., Alvarado, M., and Tobin, D.: Development and recent evaluation of the MT_CKD model of continuum absorption, Phil. Trans. R. Soc. A, 370, 2520-2556, doi:10.1098/rsta.2011.0295, 2012.

Moradi, I., Ferraro, R. R., Eriksson, P., and Weng, F.: Intercalibration and validation of observations from ATMS and SAPHIR microwave sounders, IEEE Trans. Geosci. Remote Sens., 53, 59155925, doi:10.1109/TGRS.2015.2427165, 2015.

Nash, J., Oakley, T., Vömel, H., and Wei, L.: WMO intercomparison of high quality radiosonde systems, Yangjiang, China, 12 July3 August 2010, WMO Tech. Doc. WMO/TD1580, Instruments and Observing Methods Rep. 107, 238 pp., 2011.

Ning, T., Wang, J., Elgered, G., Dick, G., Wickert, J., Bradke, M., Sommer, M., Querel, R., and Smale, D.: The uncertainty of the atmospheric integrated water vapour estimated from GNSS observations, Atmos. Meas. Tech., 9, 79-92, doi:10.5194/amt-979-2016, 2016.

Odintsova, T., Tretyakov, M., Krupnov, A. F., and Leforestier, C.: The water dimer millimeter-wave spectrum at ambient conditions: A simple model for practical applications, J. Quant. Spectrosc. Ra. Trans., 140, 75-80, doi:10.1016/j.jqrst.2014.02.016, 2014.

Payne, V., Delamere, J., Cady-Pereira, K., Gamache, R., Moncet, J.L., Mlawer, E., and Clough, S.: Air-broadened half-widths of the 22- and $183-\mathrm{GHz}$ water vapor lines, IEEE Trans. Geosci. Remote Sens., 46, 3601-3617, doi:10.1109/TGRS.2008.2002435, 2008.

Payne, V., Mlawer, E., Cady-Pereira, K., and Moncet, J.-L.: Water vapour continuum absorption in the microwave, IEEE Trans. Geosci. Remote Sens., 49, 2194-2208, doi:10.1109/TGRS.2010.2091416, 2011.

Rosenkranz, P.: Water vapor microwave continuum absorption: a comparison of measurements and models, Radio Sci., 33, 919928, 1998.
Rosenkranz, P. W.: Correction to "Water vapor microwave continuum absorption: A comparison of measurements and models", Radio Sci., 34, p. 1025, 1999.

Rothman, L. S., Gordon, I. E., Babikov, Y., Barbe, A., Chris Benner, D., Bernath, P. F., Birk, M., Bizzocchi, L., Boudon, V., Brown, L. R., Campargue, A., Chance, K., Cohen, E. A., Coudert, L. H., Devi, V. M., Drouin, B. J., Fayt, A., Flaud, J.-M., Gamache, R. R., Harrison, J. J., Hartmann, J.-M., Hill, C., Hodges, J. T., Jacquemart, D., Jolly, A., Lamouroux, J., Le Roy, R. J., Li, G., Long, D. A., Lyulin, O. M., Mackie, C. J., Massie, S. T., Mikhailenko, S., Müller, H. S. P., Naumenko, O. V., Nikitin, A. V., Orphal, J., Perevalov, V., Perrin, A., Polovtseva, E. R., Richard, C., Smith, M. A. H., Starikova, E., Sung, K., Tashkun, S., Tennyson, J., Toon, G. C., Tyuterev, Vl. G., and Wagner, G.: The HITRAN2012 molecular spectroscopic database, J. Quant. Spectrosc. Ra. Trans., 130, 4-50, 2013.

Saunders, R., Matricardi, M., and Brunel, P.: An improved fast radiative transfer model for assimilation of satellite radiance observations, Q. J. Roy. Meteor. Soc., 125, 1407-1425, 1999.

Saunders, R., Hocking, J., Rundle, D., Rayer, P., Matricardi, M., Geer, A., Lupu, C., Brunel, P., and Vidot, J.: RTTOV-11: Science and validation report, NWP-SAF report, Met Office, UK, 62 pp., 2013.

Serov, E. A., Koshelev, M. A., Odintsova, T. A., Parshin, V. V., and Tretyakov, M.: Rotationally resolved water dimer spectra in atmospheric air and pure water in the 188258 GHz range, Phys. Chem. Chem. Phys., 16, 26221-26233, doi:10.1039/C4CP03252G, 2014.

Tennyson, J., Bernath, P. F., Campargue, A., Csaszar, A. G., Daumont, L., Gamache, R. R., Hodges, J. T., Lisak, D., Naumenko, O. V., Rothman, L. S., Tran, H., Zobov, N. F., Buldyreva, J., Boone, N. D., De Vizia, M. D., Gianfrani, L., Hartmann, J. M., McPheat, R., Weidmann, D., Murray, J., Ngo, N. H., and Polyansky, O. L.: Recommended isolated-line profile for representing high-resolution spectroscopic transitions, Pure Appl. Chem., 86, 1931-1943, 2014.

Tretyakov, M. Yu.: Underlying spectroscopy for remote sensing of atmospheric water vapor, J. Molecular Spectros., in preparation, 2016.

Tretyakov, M. Y., Serov, E. A., Koshelev, M. A., Parshin, V. V., and Krupnov, A. F.: Water dimer rotationally resolved millimeterwave spectrum observation at room temperature, Phys. Rev. Lett., 110, 093001, doi:10.1103/PhysRevLett.110.093001, 2013.

Turner, D. D., Cadeddu, M. P., Löhnert, U., Crewell, S., and Vogelmann, A. M.: Modifications to the water vapor continuum in the microwave suggested by ground-based $150-\mathrm{GHz}$ observations, IEEE Trans. Geosci. Remote Sens., 47, 3326-3337, 2009.

Vömel, H., Selkirk, H., Miloshevich, L., Valverde-Canossa, J., Valdés, J., Kyrö, E., Kivi, R., Stolz, W., Peng, G., and Diaz, J. A.: Radiation dry bias of the Vaisala RS92 humidity sensor, J. Atmos. Oceanic Technol., 24, 953-963, doi:10.1175/JTECH2019.1, 2007.

Wilheit, T., Brogniez, H., Datta, S., Linwood Jones, W., Payne, V., Stocker, E., and Wang, J.: The use of SAPHIR on MeghaTropiques for intercalibration of polar-orbiting microwave water vapor sounders, 2013 EUMETSAT meteorological satellite Conference / 19th AMS Satellite Meteorology Oceanography and Climatology Conference, Vienna, Austria, 272, 2013. 
Wulfmeyer, V., Hardesty, R., Turner, D., Behrendt, A., Cadeddu, M., Di Girolamo, P., Schlüssel, P., Van Baelen, J., and Zus, F.: A review of the remote sensing of lower tropospheric thermodynamic profiles and its indispensable role for the understanding and the simulation of water and energy cycles, Rev. Geophys., 53, 819-895, doi:10.1002/2014RG000476, 2015.
Yu, H., Ciesielski, P. E., Wang, J., Kuo, H.-C., Vömel, H., and Dirksen, R.: Evaluation of humidity correction methods for Vaisala RS92 tropical sounding data, J. Atmos. Oceanic Technol., 32, 397-411, doi:10.1175/JTECH-D-14-00166.1, 2015. 